\title{
Effects on Input Use on Rapeseed and Mustard Production in Nagaon District of Assam, India
}

\author{
Kandarpa Kumar Das and Amod Sharma* \\ Department of Agricultural Economics, Nagaland University, SASRD, Medziphema Campus, \\ District: Dimapur, Nagaland - 797 106, India \\ *Corresponding author
}

\section{A B S T R A C T}

\section{Keywords}

Rapeseed and mustard crop, Resource use efficiency, Marginal value product, Marginal factor cost,

Optimum value

Article Info

Accepted:

07 April 2018

Available Online:

10 May 2018
This study was attempted to evaluate resource use efficiency in rapeseed and mustard production in Nagaon district of Assam. To conduct the study, primary data were collected from 250 farmers, selected using multistage simple random sampling technique. Data analysis was done using both inferential statistics and regression analysis using CobbDouglas production function. The Marginal Value Productivity (MVP) of resources were calculated and compared with its corresponding Marginal Factor Cost (MFC). The regression analysis revealed that there is a scope for increasing the use of the included input variables up to optimal level in order to achieve their efficient use. The sum of elasticity $\left(\sum \mathrm{b}_{\mathrm{i}}\right)$ is greater than unity, showing thereby increasing returns to scale. This indicated that any further increase in use of these resources may provide a proportionate increase in output.

\section{Introduction}

Oilseeds crops have traditionally been the backbone of agricultural economy of India. Today, India is one of the largest producers of oilseeds in the world. It accounted for an estimated production of 32.48 million tones during the year 2010-11 ${ }^{\mathrm{a}}$. Rape and Mustard comes under major edible oilseeds in India. Rapeseed and Mustard oil is consumed in India as food oil and the meal cake left after the extraction of oil forms important cattle feed. It can also be used as manure for various grain crops.

Rape and Mustard is one of the important oilseed crop in Assam, constituting 90.91 per cent of the total oilseed area ( 0.24 million ha) in $2010-2011^{\mathrm{b}}$. It contributes 90.32 per cent of the total oilseed production. Assam contributes about 1.71 per cent of total Rape and Mustard production in India and its share of area is 3.48 per cent in 2010-11.

In Assam, major rape and mustard growing districts are Nagaon, Barpeta, Lakhimpur, Darrang, Sonitpur, Kokrajhar, Kamrup etc. Nagaon district has an area of 13638 hectares and production 7762 tones with a productivity of $569 \mathrm{~kg}$ per hectare in case of rapeseed and mustard in $2010-11^{\mathrm{c}}$. The percentage share of Nagaon district in Assam in respect of area and production is 5.59 per cent and 5.44 per cent respectively. In Nagaon district during 
1980s, the compound growth rate of production of rapeseed and mustard was 9.34 per cent (Das and Sharma, 2012) which reduces to 0.69 per cent and 6.21 per cent during 1990s and 2010s respectively. So, there is a need to increase the yield level of this crop. In order to increase production further by utilizing natural resources, more emphasis is required to the correct use of major inputs and promotes progressive farming. So, the present study is an attempt to evaluate various agricultural resource use efficiency which facilitates in increasing the yield. The study hypothesized that the farmers are inefficient in resource use for production.

\section{Materials and Methods}

Production in any region is a function of interaction between natural resource endowments, inputs used and technology management. In order to measure the contribution of specific factor in combination with other factors which are responsible for the change in the level of output, multiple regression analysis was used in the form of Cobb-Douglas production function.

This function was used in this study as it is a relatively 'efficient user' of degrees of freedom. It has the advantage over other as the estimates can be computed conveniently while the other involve tedious and labourious calculations. The regression co-efficient $\left(b_{i}\right)$ in Cobb-Douglas production function directly indicate the elasticity of production which measures the percentage change in output for unit percentage in the input and also it free from the unit of measurement and factor ratio (Bhowmick, 1975). The form of the CobbDouglas production function fitted for the selected variables is as follows.

$$
y=a \cdot x_{1}^{b_{1}} \cdot x_{2}^{b_{2}} \cdot x_{3}^{b_{3}} \cdot x_{4}^{b_{4}} \cdot x_{5}^{b_{5}} \cdot x_{6}^{b_{6}} \cdot x_{7}^{b_{7}}
$$

Whereas, $\mathrm{y}=$ Output of Rapeseed and mustard in quintal,

$\mathrm{x}_{1}=$ Area in hectare,

$\mathrm{x}_{2}=$ Seed in $\mathrm{kg}$,

$\mathrm{x}_{3}=\mathrm{FYM}$ in quintal,

$\mathrm{x}_{4}=$ Fertilizer in $\mathrm{kg}(\mathrm{N}+\mathrm{P}+\mathrm{K})$,

$\mathrm{X}_{5}=$ Human labour in mandays,

$\mathrm{x}_{6}=$ Bullock labour in pairdays,

$\mathrm{x}_{7}=$ Tractor use in hours,

$\mathrm{a}=$ intercept or constant,

$b_{i} s(i=1,2,3, \ldots, 7)$ are parameters i.e., elasticity of production of the respective $\mathrm{x}_{\mathrm{i}} \mathrm{s}$.

The production function was estimated by using an ordinary least squares (OLS) method. The values of coefficient of multiple determination $\left(\mathrm{R}^{2}\right)$, Standard Error (SE) of regression coefficients $\left(b_{i} s\right)$ and $t$ values were also estimated for judging of overall significance of the production function and regression coefficients.

\section{Optimum level of resource use}

In order to know how much of a particular input could be use profitably by the rapeseed and mustard growers and to determine the input output ratio, $\mathrm{MVPx}_{\mathrm{i}}$ of each input was compared with its $\mathrm{MFCx}_{\mathrm{i}}$. The marginal value product of a particular input was worked out by solving the first order marginal condition as follows.

$M V P_{X_{i}}=\left(\frac{d y}{d x_{i}}\right) P_{Y}=\left(b_{i} \cdot \frac{\bar{Y}}{\overline{X_{i}}}\right) \cdot P_{Y}$

Optimum value $=\left(\frac{M V P_{x_{i}}}{P\left(x_{i}\right)}\right)=\left(b_{i} \cdot \frac{\bar{Y}}{P\left(x_{i}\right)}\right) \cdot P_{Y}$

Where,

$\bar{Y}=$ Geometric mean of output,

$\overline{X_{i}}=$ Geometric mean of $\mathrm{i}^{\text {th }}$ input,

$\mathrm{P}_{\mathrm{Y}}=$ Unit price of output $(\mathrm{Y})$ 
$b_{i}=$ Regression co-efficient of $i^{\text {th }}$ input $\left(X_{i}\right)$

$\mathrm{P}\left(\mathrm{x}_{\mathrm{i}}\right)=\mathrm{MFC}_{\mathrm{xi}}=$ price per unit of the $\mathrm{i}^{\text {th }}$ input $\left(\mathrm{X}_{\mathrm{i}}\right)$.

According to theory, when the ratio is greater than one, this means that the increase in output outpaces the increase in input and production is elastic. When it is less than one, this indicates that the percentage increase in output is less than the percentage increase in input and the production is said to be inelastic.

When the ratio is equal to one, then output increases by the same rate as input and elasticity is said to be unitary (Adeyemo and Kuhlmann, 2009).

\section{Sources of data and sampling procedure}

Primary data were collected from randomly selected rapeseed and mustard growing farmers in the Nagaon district of Assam during 2009-2010 agricultural crop year, then three stage sampling design was used to conduct this study. At first stage 5 (five) development blocks of Nagaon district was selected. After that 2 (two) villages from each selected block at the first stage have been selected and at the final stage 25 (twenty five) farmers were selected by Simple Random Sampling technique from each of the selected villages on the basis of 4:3:2:1 ratio of marginal, small, medium and large farmers respectively. Thus, the total number of farmers at primary level was $250(25 \times 2 \times 5)$ with an ultimate break up of 100 marginal farmers, 75 small farmers, 50 medium farmers and 25 large farmers. The categorization of household farmers into marginal, small, medium and large group was done on the basis of their operational land holdings as follows:

Marginal: less than 1 ha

Small: 1 to 2 ha

Medium: 2 to 4 ha

Large: more than 4 ha

\section{Results and Discussion}

The estimated regression coefficients and the related statistics for the regression equation are presented in Table 2. The coefficient of multiple determination $\left(\mathrm{R}^{2}\right)$ indicates that 82.73 per cent, 96.13 per cent, 95.88 per cent, 95.18 per cent and 93.52 per cent of the total variation in the output is explained by variation in the level of use of each of the specified inputs in case of marginal, small, medium, large and overall farmer respectively. From the study, it is found that the sum of the regression coefficient is greater than unity for all categories of farmers as well as overall also and it is 1.04, 1.04, 1.17, 1.09 and 1.03 for marginal, small, medium, large and overall respectively. This indicates increasing returns to scale in production which in terns indicated that any further increase in use of this resources lead to more than proportionate increase in the productivity (Singh et al., 2005). At overall level, the regression coefficients for area $\left(\mathrm{x}_{1}\right)$, seed $\left(\mathrm{x}_{2}\right)$, FYM $\left(\mathrm{x}_{3}\right)$ and tractor use $\left(\mathrm{x}_{7}\right)$ were significant at 1 per cent level. This implies that if other things keeping constant then area, seed, FYM and tractor use play significant roles in explaining the variation in rapeseed and mustard production. The F-test which is an overall test of significance for the production function equation was significant at 1 per cent level. So, the non-significant of some of the coefficients, i.e., fertilizer $\left(\mathrm{x}_{4}\right)$, human labour $\left(\mathrm{x}_{5}\right)$ and bullock labour $\left(\mathrm{x}_{6}\right)$, therefore could be accommodated within limits.

\section{Marginal value productivity}

The marginal value productivity (MVP) provides a framework for effecting resources adjustment on the farm. When the MVP is positive, it is an indication that using more of a given resources could increase output. Under perfect competition a farm will be maximizing its profit by equating MVP of each factor with 
its cost (Babatunde and Boluwade, 2013). The MVP of various resource inputs like area, seed, manure, fertilizer etc. were worked out at their geometric mean level in order to compare their productivity.

Since there is open competition, nobody will accept less than marginal productivity. For the estimation of MVP, the annual average wholesale market price was used (Singh et al., 2007). The estimates of MVP of each resource for all categories of farmers are presented in Table 1.

The MVP of all resources included under this study was found to be positive and greater than unity in case of marginal farmer. The positive sign of MVP for all the resources confirm that increasing the level of use of the resources can increase the output.

In case of small farm and overall level, all the resources except bullock labour, were found positive. Table 1 shows that area is positive for all category of farm as well as overall level and it is the most productive resources followed by seed. The very high value of MVP for area due to the fact that farmers cultivate high value crop under the study (Ogunfowora et al., 1975).

\section{Resource use efficiency}

To assess the level of resource use efficiency, the ratio of MVP to MFC of each input was computed. The price paid for a unit of input was taken as the factor cost. These costs facilitate the shifting of resources from the less remunerative uses to more profitable ones. A dynamic farming cannot function without this shifting. The difference between MVP and MFC indicates the level of the resources use. The differences give the scope of resources adjustment necessary to attain economic optimum.

The geometric mean level of input, estimated MVP of different inputs, factor price, their ratio and optimum value at overall farm level are presented in Table 3. The ratio of MVP of seed to its price was more than 8 indicating a very good scope to increase the use of this input. In case of manure, the ratio of MVP to its price was found to be more than 2 indicating good scope to use this input for profit maximization. From Table 3, it has been observed that the ratio of MVP to its MFC, in case of area, fertilizer, human labour, bullock labour and tractor use were less than 1 indicating scope to reduce the use of these inputs in profit maximization.

Table.1 Marginal value productivities of resources use in rapeseed and mustard production

\begin{tabular}{|c|c|c|c|c|c|c|}
\hline S. & \multicolumn{3}{|c|}{ Resources } & \multicolumn{5}{|c|}{ MVP } \\
\cline { 3 - 7 } No. & \multicolumn{2}{|c|}{ Marginal } & Small & Medium & Large & overall \\
\hline 1. & Area in ha & 2905.17 & 636.64 & 19623.18 & 16871.07 & 9701.93 \\
\hline 2. & Seed in kg & 419.19 & 1077.87 & -102.25 & 70.41 & 343.75 \\
\hline 3. & FYM in qtl & 134.71 & 271.51 & 317.40 & 782.21 & 177.57 \\
\hline 4. & Fertilizer in kg & 1.53 & 0.88 & 0.66 & 2.52 & 0.85 \\
\hline 5. & Human labour in MD & 123.03 & 70.36 & -5.70 & -97.85 & 34.57 \\
\hline 6. & Bullock labour in PD & 26.21 & -53.89 & 32.55 & 115.59 & -4.60 \\
\hline 7. & Tractor use in hrs & 238.63 & 153.31 & -19.91 & -84.53 & 126.34 \\
\hline
\end{tabular}


Table.2 Regression co-efficient, standard error and co-efficient of multiple determination $\left(\mathrm{R}^{2}\right)$ of resources used for cultivation of rapeseed and mustard crop in Nagaon district of Assam

\begin{tabular}{|c|c|c|c|c|c|c|c|c|c|c|c|c|c|}
\hline \multirow{2}{*}{$\begin{array}{l}\text { S. } \\
\text { No. }\end{array}$} & \multirow{2}{*}{$\begin{array}{l}\text { Type of } \\
\text { farm }\end{array}$} & \multirow{2}{*}{$\begin{array}{l}\text { Sample } \\
\text { size }\end{array}$} & \multicolumn{8}{|c|}{ Regression Co-efficient } & \multirow[b]{2}{*}{$\begin{array}{l}\mathbf{R}^{2} \\
(\%)\end{array}$} & \multirow[b]{2}{*}{ F ratio } & \multirow[b]{2}{*}{$\sum \mathbf{b}_{\mathbf{i}}$} \\
\hline & & & Intercept & $\begin{array}{l}\text { Area in } \\
\text { ha } \\
\qquad\left(\mathbf{X}_{1}\right)\end{array}$ & $\begin{array}{l}\text { Seed } \\
(\mathbf{k g}) \\
\left(\mathbf{X}_{2}\right)\end{array}$ & $\begin{array}{l}\text { FYM } \\
(\mathbf{q t l}) \\
\left(\mathbf{X}_{3}\right)\end{array}$ & $\begin{array}{l}\text { Fertilizer } \\
(\mathbf{k g}) \\
\left(\mathrm{X}_{4}\right)\end{array}$ & $\begin{array}{l}\text { Human } \\
\text { Labour } \\
(\mathrm{MD})\left(\mathrm{X}_{5}\right)\end{array}$ & $\begin{array}{l}\text { Bullcok } \\
\text { Labour } \\
(\mathrm{PD})\left(\mathrm{X}_{6}\right)\end{array}$ & $\begin{array}{l}\text { Tractor } \\
\text { use (hrs) } \\
\left(\mathrm{X}_{7}\right)\end{array}$ & & & \\
\hline 1. & Marginal & 100 & $\begin{array}{l}-0.3097 \\
(0.3896)\end{array}$ & $\begin{array}{c}0.1603 \\
(0.2427)\end{array}$ & $\begin{array}{c}0.2172 \\
(0.1668)\end{array}$ & $\begin{array}{c}0.0620 \\
(0.0439)\end{array}$ & $\begin{array}{c}0.0161 \\
(0.0112)\end{array}$ & $\begin{array}{l}0.4359 * \\
(0.2190)\end{array}$ & $\begin{array}{c}0.0226 \\
(0.0276)\end{array}$ & $\begin{array}{l}0.1338^{*} \\
(0.0679)\end{array}$ & 82.73 & $62.96 * *$ & 1.04 \\
\hline 2. & Small & 75 & $\begin{array}{c}-0.2860 \\
(0.1923)\end{array}$ & $\begin{array}{c}0.0366 \\
(0.1327)\end{array}$ & $\begin{array}{c}0.5377 * * \\
(0.1073)\end{array}$ & $\begin{array}{c}0.1543 * * \\
(0.0524)\end{array}$ & $\begin{array}{c}0.0099 \\
(0.0129)\end{array}$ & $\begin{array}{l}0.2638^{*} \\
(0.1122)\end{array}$ & $\begin{array}{c}-0.0501 * \\
(0.0211)\end{array}$ & $\begin{array}{c}0.1032 * * \\
(0.0359)\end{array}$ & 96.13 & $237.54 * *$ & 1.04 \\
\hline 3. & Medium & 50 & $\begin{array}{c}0.8893 * * \\
(0.1697)\end{array}$ & $\begin{array}{l}1.1213 * * \\
(0.1047)\end{array}$ & $\begin{array}{l}-0.0552 \\
(0.0393)\end{array}$ & $\begin{array}{l}0.1098^{*} \\
(0.0496)\end{array}$ & $\begin{array}{c}0.0066 \\
(0.0099)\end{array}$ & $\begin{array}{c}-0.0173 \\
(0.1307)\end{array}$ & $\begin{array}{c}0.0210 \\
(0.0500)\end{array}$ & $\begin{array}{l}-0.0114 \\
(0.0546)\end{array}$ & 95.88 & $139.71 * *$ & 1.17 \\
\hline 4. & Large & 25 & $\begin{array}{l}0.9425^{*} \\
(0.3704)\end{array}$ & $\begin{array}{l}0.9344 * \\
(0.3872)\end{array}$ & $\begin{array}{c}0.0353 \\
(0.3579)\end{array}$ & $\begin{array}{c}0.3428 * * \\
(0.0940)\end{array}$ & $\begin{array}{c}0.0295 \\
(0.0149)\end{array}$ & $\begin{array}{c}-0.2789 \\
(0.1578)\end{array}$ & $\begin{array}{c}0.0702 \\
(0.0491)\end{array}$ & $\begin{array}{l}-0.0407 \\
(0.0589)\end{array}$ & 95.18 & $47.91 * *$ & 1.09 \\
\hline & erall & 250 & $\begin{array}{c}0.3171 \\
(0.1254)\end{array}$ & $\begin{array}{c}0.5460 * * * \\
(0.0820)\end{array}$ & $\begin{array}{c}0.1769 * * * \\
(0.0515)\end{array}$ & $\begin{array}{c}0.0824 * * \\
(0.0266)\end{array}$ & $\begin{array}{c}0.0108 \\
(0.0069)\end{array}$ & $\begin{array}{c}0.1327 \\
(0.0719)\end{array}$ & $\begin{array}{c}-0.0037 \\
(0.0132)\end{array}$ & $\begin{array}{c}0.0827 * * 6 \\
(0.0246)\end{array}$ & 93.52 & $498.86 * *$ & 1.03 \\
\hline
\end{tabular}

(*** Significant at 1 per cent, ${ }^{* *}$ Significant at 5 per cent and $*$ Significant at 10 per cent level of probability)

Table.3 Regression co-efficient, standard error, marginal value product (MVP) to factor cost ratio, present value and optimum value of resources used for cultivation of rapeseed and mustard crop at overall farm level in Nagaon district of Assam

\begin{tabular}{|c|l|c|c|c|c|c|c|c|}
\hline S. No. & Resources & $\begin{array}{l}\text { Regression Co- } \\
\text { efficient }\end{array}$ & $\begin{array}{l}\text { Standard } \\
\text { Error }\end{array}$ & $\begin{array}{l}\text { Geometric } \\
\text { Mean }\end{array}$ & MVP & $\begin{array}{l}\text { Ratio of } \\
\text { MVP }\end{array}$ & $\begin{array}{l}\text { Present } \\
\text { value }\end{array}$ & $\begin{array}{l}\text { Optimum } \\
\text { value }\end{array}$ \\
\hline 1. & Area in ha & $0.5460 * *$ & 0.0820 & 0.31 & 9701.93 & 0.02 & 0.31 \\
\hline 2. & Seed in kg & $0.1769 * *$ & 0.0515 & 2.82 & 343.75 & 8.59 & 2.82 \\
\hline 3. & FYM in qtl & $0.0824 * *$ & 0.0266 & 2.54 & 177.57 & 2.96 & 2.54 \\
\hline 4. & Fertilizer in kg & 0.0108 & 0.0069 & 69.55 & 0.85 & 0.11 & 69.55 \\
\hline 5. & Human labour in MD & 0.1327 & 0.0719 & 20.99 & 34.57 & 0.29 & 20.99 \\
\hline 6. & Bullock labour in PD & -0.0037 & -0.0132 & 4.40 & -4.60 & -0.03 & 4.40 \\
\hline 7. & Tractor use in hrs & $\mathbf{0 . 0 8 2 7 * *}$ & $\mathbf{0 . 0 2 4 6}$ & $\mathbf{3 . 5 8}$ & $\mathbf{1 2 6 . 3 4}$ & $\mathbf{0 . 9 7}$ & $\mathbf{6 . 0 9}$ \\
\hline
\end{tabular}

(*** Significant at 1 per cent, ** Significant at 5 per cent and $*$ Significant at 10 per cent level of probability) 


\section{Optimum level of input}

The estimated optimum level and the ratio of MVP to its factor price in respect of all the input use under this study are presented in Table 3. From the analysis, it is revealed that the optimum level is more than present level of use in case of seed and FYM at overall farm level. This indicates that there is a scope to utilize these two input use. So, to increase the output at profit maximization level, more seed and FYM should be used. The optimum value is lower than the present value in case of area, fertilizer use, human labour, bullock labour and tractor use. This implies that increase in output may not be achieved by adjusting the level of use of these inputs.

This study provides some useful information on resource use and efficiency in rapeseed and mustard production in Nagaon district of Assam. The study showed that the estimated values of elasticity coefficients of production function for the most of the included variables were positive and significant indicating positive influence on the productivity. In all categories of farm, the sum of elasticity $\left(\sum \mathrm{b}_{\mathrm{i}}\right)$ is greater than unity, showing thereby increasing returns to scale. This indicated that any further increase in use of these resources would lead to more than proportionate increase in the productivity. The result of the regression analysis showed that most of the included inputs were significant in explaining the variation in the output of study crop. This indicated that all the independent variables had influencing effect on the output of the crop. Resource use efficiency analysis revealed that there is a scope to utilize seed and manure input compared to other input use.

To achieve increase in the output of rapeseed and mustard crop and increased resources productivity, the following measures are suggested. Rapeseed and mustard growing farmers should acquire modern farm tools and equipments that would enable them to increase the size of farmland. Farmers need to be trained in the sufficient use of input use. The use of labour should be reduced by adopting farm mechanization and modern farming technique. This will be helpful in transforming from subsistence farming to commercial farming.

\section{References}

Adeyemo, R. and Kuhlmann, F. 2009. Resource use efficiency in urban agriculture in southwestern Nigeria, Tropicultura. 27 (1): 49-53.

Babatunde, R. O. and Boluwade, E. O. 2013. Resource use in food crop production in Ekiti state, Nigeria, Journal of Agriculture and Social Research. 4 (1): 105-117.

Bhowmick, B. C. 1975. Resource productivity, allocation and farm profitability of jute and paddy in Kamrup district of Assam, M. Sc. (Agri) Thesis submitted to Jawaharlal Nehru Krishi Vishwa Vidyalaya, Jabalpur (Unpublished).

Ogunfowora, O.; Essang, S. M. and Olayide, S. O. 1975. Resource productivity in traditional agriculture: a case study of four agriculture division of Kwara state of Nigeria, Journal of Rural Economics and Development. 9 (1): 119-131.

Singh, R. S.; Singh, V. V. and Shrivastava, P. 2005. Input use and food grain production relationship in Indian agriculture. Agricultural Situation in India. 52 (1): 1931.

Singh, S. P.; Gangwar, B. and Garg, B. M. 2007. Input use efficiency - a comparative study of rice-wheat and sugarcane-ratoon cropping system in mid-western plain of $\mathrm{U}$. P. Agricultural Situation in India. 54 (8): 377-383.

\section{How to cite this article:}

Kandarpa Kumar Das and Amod Sharma. 2018. Effects on Input Use on Rapeseed and Mustard Production in Nagaon District of Assam, India. Int.J.Curr.Microbiol.App.Sci. 7(05): 629-634. doi: https://doi.org/10.20546/ijcmas.2018.705.077 